\title{
Bias u kliničkim istraživanjima
}

Bias in clinical trials

\author{
Goran Poropat ${ }^{1 *}$, Andrea Kresović ${ }^{2}$ Davor Štimac ${ }^{1}$
}

Sažetak. Bias ili sustavna pogreška koja se javlja u istraživanjima u današnje je vrijeme velik teret za medicinu temeljenu na dokazima (engl. Evidence based medicine - EBM). Takve pogreške mogu se javiti u bilo kojoj fazi istraživanja i uvelike utječu na rezultate i vjerodostojnost neke terapije ili postupka. Postoje razne metode kojima se može na vrijeme prepoznati i izbjeći bias te je preporučljivo njihovo korištenje.

Ključne riječi: bias; Cochrane Handbook; funnel plot; randomizirana klinička ispitivanja; zasljepljivanje

Abstract. Bias or systematic error which occurs during trials is a heavy load on Evidence based medicine (EBM). Such errors can occur in any trial phase and they can affect greatly the results and credibility of a certain trial or procedure. There are various metods which can help identify and avoid bias. The use of these metods is highly recommended.

Key words: bias; blinding; Cochrane Handbook; funnel plot; randomized clinical trials

${ }^{1}$ Zavod za gastroenterologiju, Klinika za internu medicinu, Klinički bolnički centar Rijeka, Rijeka ${ }^{2}$ Medicinski fakultet Rijeka, Sveučilište u Rijeci, Rijeka

\section{*Dopisni autor:}

doc. dr. sc. Goran Poropat, dr. med. Zavod za gastroenterologiju, Klinika za internu medicinu Klinički bolnički centar Rijeka Krešimirova 42, 51000 Rijeka, Hrvatska e-mail: gporopat8@gmail.com

http://hrcak.srce.hr/medicina 


\section{UVOD}

Bias se u kliničkim istraživanjima može opisati kao sustavna pogreška koja potiče jedan rezultat naspram ostalih ${ }^{1}$. Učinak biasa na istraživanje može biti velik, od donošenja pogrešnih zaključaka do preporučanja postupaka koji su potencijalno štetni. U radu će se opisati različite vrste biasa povezane s određenom fazom istraživanja u kojem se javljaju. Na kraju će biti navedene preporuke o tome kako na vrijeme prepoznati i što učinkovitije izbjeći bias.

Bias u kliničkim istraživanjima može se opisati kao sustavna pogreška koja potiče jedan rezultat naspram ostalih.

\section{BIAS PRIJE POČETKA ISTRAŽIVANJA}

Prije početka istraživanja bias se može dogoditi u dvije situacije, pogreške u dizajniranju studije i pogreške pri odabiru sudionika istraživanja². Ovakvi propusti ne mogu se nadoknaditi niti u jednom drugom segmentu istraživanja. Prilikom dizajniranja i planiranja studije i svrstavanju sudionika u skupine poželjno je upotrebljavati objektivne i standardizirane modele poput Breast $\mathrm{Q}$ modela u plastičnoj kirurgiji (alat pomoću kojeg se mjeri uspješnost tretmana sa stajališta pacijenta) ili Caprini skale (omogućuje objektivnu procjenu rizika od duboke venske tromboze) ${ }^{3}$. Pojavljivanjem randomiziranih kliničkih istraživanja ove vrsta biasa svedene su na minimum. $U$ takvim istraživanjima sudionici se svrstavaju u skupine slučajnim odabirom te oni sami ne znaju u kojoj su skupini (jednostruko slijepi pokusi). Dodatno onemogućavanje uvida bolničkom osoblju u status sudionika (dvostruko slijepi pokusi) također smanjuje rizik biasa. Na taj način onemogućujemo pogreške povezane $s$ očekivanjima sudionika ili osoblja. Ako to nije moguće, onda se može razmisliti o opciji uvođenja različitog osoblja u raznim fazama istraživanja koje nije upućeno u postupke koji su se obavljali. Također je moguće provoditi trostruko, četverostruko i peterostruko slijepe pokuse u kojima niti sakupljači podataka, analitičari i osobe koje će pisati sam tekst rada nisu upoznati sa skupinama sudionika.
Odabir sudionika za istraživanje može se pokazati kao mogući izvor biasa. Idealna skupina sudionika jasno je definirana, lako dostupna, pouzdana i ima veću mogućnost razvijanja točnijeg rezultata².

\section{BIAS TIJEKOM ISTRAŽIVANJA}

U samom tijeku istraživanja bias se najčešće događa prilikom prikupljanja i obrade podataka (engl. information bias). Na samom početku imamo bias ispitivača (engl. interviewer bias); ispitivač čini pogrešku tako što određenoj skupini sudionika postavlja pitanja na sugestivniji način ili postavlja različita pitanja prilikom prikupljanja podataka. Ovakva situacija može se izbjeći ako ispitivač nije upoznat sa statusom sudionika, tzv. zasljepljivanje (engl. blinding). Pogreške razradbenog postupka (engl. misclassification bias) događaju se kada su sudionici svrstani u krive skupine. ${ }^{4}$ Potencijalni izvor ovih pogrešaka može biti u upotrebi neadekvatnih instrumentalnih metoda, poput korištenja iste veličine manšeta za tlakomjer za mršave i pretile ispitanike, što dovodi do netočnih rezultata. Pogreške sjećanja (engl. recall bias) odnose se na fenomen pri kojem odgovor na neki postupak ili terapiju utječe na pacijentova sjećanja o događajima neposredno prije ili poslije tog postupka, odnosno intervencije. ${ }^{2}$ Najpoznatiji primjer recall biasa jest vjerovanje da je MMR cjepivo povezano s nastankom autizma kod djece (zato što se prvi znakovi autizma javljaju u vrijeme primanja cjepiva). Također, pacijenti sudionici istraživanja bolje će se sjećati svih čimbenika rizika povezanih sa svojom bolešću nego zdrava kontrolna skupina. Nakon toga dolazi gubitak sudionika istraživanja (engl. loss to follow up bias) koji se ne pojave na redovitim kontrolama. U tom slučaju istraživači moraju zaključiti jesu li sudionici imali drugačiji odgovor na neku određenu intervenciju od ostatka grupe, te kako ih svrstati u završnoj analizi istraživanja. Također, gubitak sudionika može ukazivati na pojavu nuspojava ispitivanog tretmana, zbog kojih dolazi do odustajanja ili nesuradljivosti (engl. compliance), što može biti bitno za istraživanje, ali se vrlo često ne spominje. Na kraju, treba spomenuti i bias u izvođenju određenog postupka, npr. operativnog zahvata. Različiti kirurzi mogu izvesti istu operaciju na drugačiji način, čak i isti kirurg neće svaki put 
ponoviti identični postupak. Iskustvo kirurga može uvelike utjecati na ishod operativnog zahvata.

\section{BIAS NAKON ZAVRŠETKA ISTRAŽIVANJA}

Nakon završetka istraživanja bias se najčešće događa prilikom analize podataka ili publikacije rada. ${ }^{2}$ Publikacijski bias (engl. publication bias) u današnje vrijeme jedan je od najčešćih biasa općenito. Radi se o tome da određen rad ili istraživanje ima puno veću mogućnost publikacije ako su mu rezultati pozitivni. S druge strane, istraživanja s negativnim rezultatima vrlo se rijetko objavljuju. Radovi poznatih autora ili institucija također imaju veći uspjeh kod publikacije, kao i oni podrijetlom iz razvijenog svijeta i zapadnih zemalja. Postoje snažni dokazi da istraživanja koja financira određena industrija najčešće pokazuju rezultate $u$ korist tih industrija (za razliku od neovisnih istraživanja). Studija provedena u Sydneyju proučavala je publikacijski status svih istraživanja podnesenih etičkom odboru u razdoblju od 10 godina ${ }^{5}$. Istraživači su došli do zaključka da istraživanja s pozitivnim rezultatima imaju puno veću mogućnost objavljivanja od onih čiji su rezultati negativni. Također, vrijeme objavljivanja je znatno kraće $(4,7 \text { godina naspram } 8 \text { godina })^{5}$. Istraživanja čiji su zaključci neodređeni imaju još lošiji položaj. Kako bi se adresirao problem publication biasa, International Committee of Medical Journal Editors (ICMJE) 2004. godine objavio je konsenzus prema kojem sva istraživanja moraju biti registrirana, jer u suprotnom neće imati mogućnost publikacije u partnerskim časopisima ${ }^{2}$. Prema tome, u njihovim registrima postoji mogućnost pronalaženja radova koji nisu objavljeni. lako se danas puno radi na smanjivanju publication biasa, on i dalje ostaje velik problem, posebice stoga što može dovesti do precjenjivanja učinka nekog postupka ili terapije.

\section{KAKO PREPOZNATI I IZBJEĆI BIAS}

Kako bi se na što učinkovitiji i lakši način umanjio bias, u bilo kojoj fazi istraživanja predlažu se dvije metode. Prva je takozvani funnel plot testa, a druga korištenje priručnika Cochrane (engl. Cochrane Handbook), u kojem su opisani načini kako na vrijeme prepoznati i spriječiti bias ${ }^{6,7}$. Funnel plot test je grafička metoda za otkrivanje prisutnosti publikacijskog biasa. Ako nije prisutan, graf će sličiti na simetrični, obrnuti dimnjak (engl. funnel), dok će u suprotnoj situaciji graf biti nepravilnog oblika.

Cochrane Handbook sadrži nekoliko poglavlja posvećenih opisu, otkrivanju i sprječavanju biasa. Svi njihovi radovi i istraživanja moraju proći provjeru na rizik od biasa. Prema Cochrane Handbooku najbolja skupina preglednih autora koji će ocijeniti rizik od biasa uključuje stručnjake područja teme rada i metodologe ${ }^{7}$. Također, potreb-

Sustavne pogreške u kliničkim istraživanjima mogu značajno utjecati na našu percepciju znanstvenih istraživanja i rezultirati njihovim pogrešnim shvaćanjem.

no je odlučiti hoće li pregledni autori biti upućeni u imena istraživača i naslove radova. Zasljepljivanje može oduzimati puno vremena i može se pokazati nemogućim kod poznatih studija. Određena istraživanja čak pokazuju da zasljepljivanje u ovom slučaju nema pozitivnih učinaka ili su oni zanemarivi ${ }^{7}$. Odluka se donosi procjenom prednosti i mana zasljepljivanja za svaku provjeru biasa zasebno. Često se javlja potreba za prikupljanjem dodatnih podataka od samih istraživača. Pri tome je važno paziti na koji način se pristupa istraživačima i na koji način se formulira molba, jer može doći do prikupljanja pretjerano pozitivnih odgovora ${ }^{7}$. Pregledni autori pritom moraju koristiti pitanja otvorenog tipa, poput: "Molim Vas, opišite sve mjere poduzete prilikom svrstavanja sudionika u skupine" za razliku od direktnih pitanja. Na taj način se osiguravaju realniji odgovori.

Cochrane Handbook nudi alat pomoću kojeg pregledni autori procjenjuju rizik od biasa. Taj alat sastoji se od dva dijela, fokusira se na sedam domena (slika 1$)^{7}$. U prvom dijelu procjene rizika ocjenjuje se na koji način je istraživanje provedeno u sklopu domena, da bi se u drugom dijelu zaključilo koliki je rizik od biasa u svakoj domeni. Rizik se može okarakterizirati kao nizak, visok ili nejasan (tablica 1$)^{7}$.

U prvoj domeni procjenjuje se na koji način su sudionici istraživanja svrstani u skupine. Smatra se da su randomizirani načini odabira sudionika naj- 


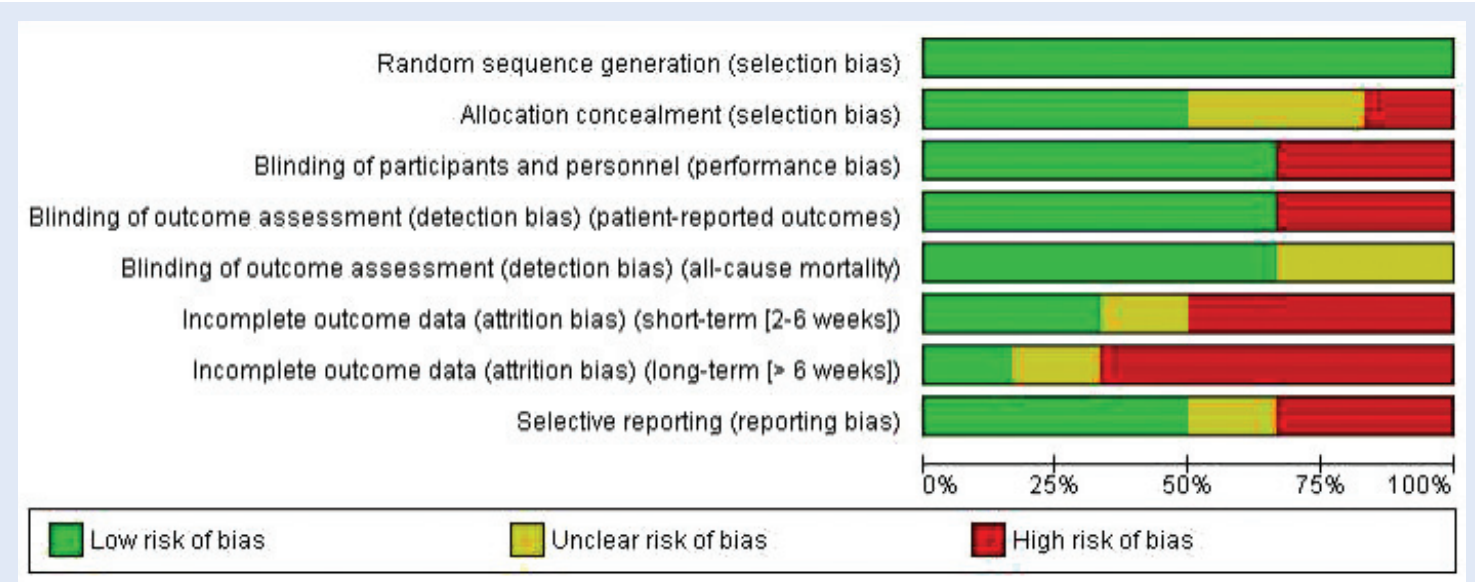

Slika 1. Primjer grafičkog prikaza rizika sustavne pogreške (bias) (preuzeto s ref. 7)

Tablica 1. Mogući pristup sažimanju procjene rizika sustavne pogreške za pojedine domene unutar i kroz studije (prilagođeno prema ref. 7)

\begin{tabular}{|l|l|l|l|}
\hline $\begin{array}{l}\text { Rizik sustavne } \\
\text { pogreške }\end{array}$ & \multicolumn{1}{|c|}{ Interpretacija } & \multicolumn{1}{|c|}{ Unutar studije } & \multicolumn{1}{c|}{ Kroz studije } \\
\hline Nizak rizik & $\begin{array}{l}\text { Moguća sustavna pogreška } \\
\text { vjerojatno neće značajnije utjecati na } \\
\text { rezultate }\end{array}$ & $\begin{array}{l}\text { Nizak rizik sustavne pogreške za sve } \\
\text { ključne domene }\end{array}$ & $\begin{array}{l}\text { Većina informacija potječe iz studija } \\
\text { s niskim rizikom sustavne pogreške }\end{array}$ \\
\hline Nejasan rizik & $\begin{array}{l}\text { Moguća sustavna pogreška koja } \\
\text { izaziva sumnju u rezultate }\end{array}$ & $\begin{array}{l}\text { Nejasan rizik sustavne pogreške za } \\
\text { jednu ili više ključnih domena }\end{array}$ & $\begin{array}{l}\text { Većina informacija potječe iz studija } \\
\text { s niskim ili nejasnim rizikom sustavne } \\
\text { pogreške }\end{array}$ \\
\hline Visoki rizik & $\begin{array}{l}\text { Moguća sustavna pogreška značajno } \\
\text { umanjuje pouzdanost rezultata }\end{array}$ & $\begin{array}{l}\text { Visok rizik sustavne pogreške u } \\
\text { jednoj ili više ključnih domena }\end{array}$ & $\begin{array}{l}\text { Udio informacija iz studija s visokim } \\
\text { rizikom sustavne pogreške dovoljan } \\
\text { je da značajno utječe na } \\
\text { interpretaciju rezultata }\end{array}$ \\
\hline
\end{tabular}

Kritičkim pristupom i poznavanjem metodologije $u$ stručnom i znanstvenom radu smanjujemo mogućnost nepravilne interpretacije rezultata i pogrešnog zaključivanja. nja sudionika u skupine važno je za procjenu rizika od biasa jer se tako osigurava potpuna randomizacija. Nakon podjele u skupine ponekad nije moguće potpuno dvostruko zasljepljivanje (npr. kod usporedbe uspjeha kirurških i farmakoloških metoda). Važno je procijeniti tko je točno bio zaslijepljen, jer se termin dvostruko slijepo (engl. double blind) vrlo često koristi ${ }^{7}$. Ako se radi o istraživanju gdje zasljepljivanje nije u potpunosti provedeno, bitno je saznati tko je bio zaslijepljen a tko nije, te procijeniti kako je to utjecalo na rezultate istraživanja.

Nakon toga slijedi domena u kojoj se analizira nedostatak podataka u istraživanju. Nedostatak se može pojaviti iz raznih razloga, poput odustajanja sudionika ili njihove nesuradljivosti, gubitka podataka i drugih. Da bi istraživanje imalo nizak rizik od biasa, svi sudionici moraju završiti istraživanje, osim u slučaju kad se za neke sudionike naknadno otkrije da nisu pogodni za istraživanje. Tada je njihovo isključivanje opravdano. $\mathrm{S}$ druge strane, 
isključivanje sudionika radi nepostizanja željenog učinka, a da se pri tome ne izjednače sve skupine u broju, može predstavljati visok rizik od biasa ${ }^{7}$. Također, događaju se situacije u kojima se sudionicima koji su odustali dodjeljuje srednja vrijednost ishoda za njihovu skupinu, što predstavlja vrlo visok rizik od biasa.

Selektivno izvještavanje rezultata slijedeća je domena za koju se procjenjuje rizik od biasa. Zbog publikacijskog biasa preferiraju se istraživanja $\mathrm{s}$ pozitivnim rezultatima i to često navodi istraživače na selektivnu objavu rezultata. Metode provjere selektivnog izvještavanja nisu dobro razvijene, ali može se koristiti uspoređivanje rezultata protokola istraživanja s objavljenim rezultatima i usporedba s drugim, sličnim istraživanjima.

Navedene domene su važni izvori biasa te su zato izdvojene. Posljednja domena alata Cochrane obuhvaća sve ostale potencijalne izvore koji nisu spomenuti dosada. Ovdje spadaju doza ispitivanog lijeka, vrijeme do kontrolnog pregleda i karakteristike sudionika. Često se događa da "stari" lijekovi budu u premaloj ili prevelikoj dozi pa, u usporedbi s njima, ispitivani lijek ima bolje karakteristike ${ }^{8}$. Takva istraživanja imaju visok rizik od biasa.

\section{ZAKLJUČAK}

Bias se može pojaviti u svim fazama istraživanja, te je izuzetno bitno na vrijeme ga prepoznati i spriječiti. Poznavanje njegovih raznih oblika omo- gućuje čitateljima kritično raspoznavanje vrijednosti nekog istraživanja te donošenje pravilnih zaključaka o potencijalnom dobrom učinku ili čak štetnosti određene terapije ili postupka, što je vrlo važno za prakticiranje medicine temeljene na dokazima (engl. Evidence based medicine - EBM).

Izjava o sukobu interesa: autori izjavljuju da ne postoji sukob interesa.

\section{LITERATURA}

1. Gluud LL. Bias in clinical intervention research. Am J Epidemiol 2006;163:493-501.

2. Pannucci $\mathrm{CJ}$, Wilkins EG. Identifying and avoiding bias in research. Plast Reconstr Surg 2010;126:619-25.

3. Pusic AL, Klassen AF, Scott AM, Klok JA, Cordeiro PG, Cano SJ. Development of a new patient-reported outcome measure for breast surgery: The BREAST-Q. Plast Reconstr Surg 2009;124:345-53.

4. Tripepi G, Jager KJ, Dekker FW, Wanner C, Zoccali C. Bias in clinical research. Kidney Int 2008;73:148-53.

5. Stern JM, Simes RJ. Publication bias: evidence of delayed publication in a cohort study of clinical research projects. BMJ1997;315;640-5.

6. Egger M, Davey Smith G, Schneider M, Minder C. Bias in meta-analysis detected by a simple, graphical test. BMJ 1997;315:629-34.

7. Higgins JPT, Altman DG, Jonathan AC. Chapter 8: Assessing risk of bias in included studies. In: Higgins JPT, Green S (eds). Cochrane Handbook for Systematic Reviwes of Interventions Version 5.1.0 [updated March 2011]. The Cochrane Collaboration, 2011. Available from: www.handbook.cochrane.org.

8. Every-Palmer S, Howick J. How evidence based medicine is failing due to biased trials and selective publication. J Eval Clin Pract 2014;20:908-14. 